Rev. Elet. em Gestão, Educação e Tecnologia Ambiental (e-ISSN: 2236-1170)

\title{
AVALIAÇÃO AMBIENTAL CORRELACIONADA AO APROVEITAMENTO TURÍSTICO DO CAJUEIRO DE PIRANGI/RN: MEDIDAS DE CONTROLE E CONTINGÊNCIA
}

\author{
I. S. Gomes' e C. E. M. Jerônimo² \\ 'Especialização em Perícia e Gestão Ambiental - UNI-RN. E-mail: ilmagomes15@yahoo.com.br \\ ${ }^{2}$ Doutor em Eng. Química (Ênfase em Eng. Ambiental). E-mail: c_enrique@hotmail.com
}

\section{RESUMO}

No Rio Grande do Norte, um dos marcos desse patrimônio natural é o cajueiro de Pirangi, sendo um dos principais destinos turísticos do estado, sendo visitado anualmente por pessoas do mundo todo que são atraídas pelo título de "Maior Cajueiro do Mundo". Entretanto, a copa do cajueiro tem se projetado de maneira destacada nos sentidos leste/oeste, com expansão dos galhos sobre o asfalto; sendo esse comportamento explicado pela posição do sol (nascente e poente). No entanto seu crescimento anual se dá em todas as direções favorecendo impactos as comunidades circunvizinhas. Como forma de subsidiar elementos para a discussão técnica e aspectos da preservação do cajueiro de Pirangi-RN, este trabalho desenvolveu o levantamento das principais alternativas técnicas para sanear os impactos do crescimento desordenado desse forte elemento turístico da região, buscando manter a atividade na região. Bem como, foram avaliadas as principais rotas de preservação do Cajueiro, mostrando os aspectos relativos a poda como um dos pontos fundamentais de como se portar com o crescimento do mesmo, sem agredir ao Meio Ambiente e mitigando impactos as atividades turísticas da região. Os principais pontos observados com o trabalho remetem que a podação é a técnica mais adequada para conter o crescimento desordenado da espécie e manter ativa esse poderoso elemento turístico da região e que as intervenções devem ser bem planejadas, sobretudo, com a escolha de períodos adequados para mitigar efeitos adversos no cajueiro.

PALAVRAS-CHAVE: Maior cajueiro do mundo; turismo; Pirangi.

\section{ABSTRACT}

In Rio Grande do Norte, one of the hallmarks of this natural heritage is the cashew Pirangi, being a major tourist destination in the state, is visited annually by people throughout the world who are attracted by the title of "World's Largest Cashew Tree." However, the cashew tree canopy has been designed so prominent in the directions east/west, with branches spread over the asphalt, this behavior is explained by the position of the sun (east and west). However annual growth occurs in all directions favoring impacts surrounding communities. As a way of supporting elements for discussion and technical aspects of preservation of cashew Pirangi-RN, this work developed a technical survey of the main alternatives to redress the impacts of uncontrolled growth strong element of tourism in the region, seeking to maintain activity in the region. As well, we evaluate the main routes to preserve the cashew tree, showing aspects of pruning as one of the key points of how to behave with the same growth, without damaging the environment and mitigating the impacts of tourist activities in the region. The main points relate to the work that pruning is the most appropriate method to contain the uncontrolled growth of the species and 
Rev. Elet. em Gestão, Educação e Tecnologia Ambiental (e-ISSN: 2236-1170)

maintain this powerful element active region's tourism and that interventions must be well planned, especially with the choice of the appropriate periods for mitigate adverse effects on cashew.

KEYWORDS: High cashew in the world, tourism, Pirangi.

\section{INTRODUÇÃO}

Um dos principais desafios do turismo é a implementação de modelos de gestão adequados e eficazes, que proporcionem desenvolvimento em dimensões econômica, social e cultural, considerando a melhoria da qualidade de vida das comunidades, por meio da geração de oportunidades de negócios, emprego e renda, conforme descreve Tomazzoni (2008).

Em nome da modernização e da atualização, despreza-se a conservação dos recursos naturais e as mudanças nos paradigmas de preservação do meio ambiente; ao mesmo tempo, em que os avanços sociais proporcionados por ela provocam desejos por mais mudança. Muitos conhecimentos tornam-se descartáveis, e as experiências são questionáveis. "Fenômenos, coisas, situações, eventos negam a riqueza e, às vezes, encobrem histórias e fatos passados que geraram as realizações" (Chia, 1999). O turismo tem, entretanto, a propriedade de promover a valorização dos acervos a patrimônios, sejam eles histórico-culturais ou naturais.

No Rio Grande do Norte, um dos marcos desse patrimônio natural é o cajueiro de Pirangi, sendo um dos principais destinos turísticos do estado, sendo visitado anualmente por pessoas do mundo todo que são atraídas pelo título de "Maior Cajueiro do Mundo", conforme descreve SETUR-RN (2012).

Considerado como o maior cajueiro do mundo tem a sua localização no distrito de Pirangi do Norte, pertencente ao município de Parnamirim. A árvore cobre uma área de aproximadamente $7500 \mathrm{~m}^{2}$, com um perímetro de aproximadamente $500 \mathrm{~m}$ (GUIA NATAL, 2004). O cajueiro localizado em Pirangi/RN possui um grande diferencial em relação aos demais indivíduos de sua espécie, é portador de uma anomalia até então não identificada em nenhum outro exemplar, é uma espécie impar, e suas características não são transmissíveis aos seus descentes através de suas sementes (reprodução sexuada). Durante o período da safra, o cajueiro produz em média cerca de sessenta mil frutos anual (Luna, 1999; Barros, 2002).

O Cajueiro tem grande importância cultural, econômica e social para a região, no entanto, o crescimento natural do vegetal tem provocado uma série de conflitos principalmente nas áreas adjacentes a este, uma vez que a área onde o mesmo está inserido é de intensa ocupação urbana, não existindo mais espaço para sua expansão (Barros; Crisóstomo, 1995). A copa do cajueiro continua crescendo sobre a área cercada, invadindo as vias de acesso ao seu redor e provocando grandes congestionamentos, principalmente na alta estação turística, o que tem levado a uma série de discussões a respeito da poda ou não da copa do vegetal, conforme descreve IDEMA (2009).

Segundo Medeiros Neto (2008) a copa do cajueiro tem se projetado de maneira destacada nos sentidos leste/oeste, com expansão dos galhos sobre o asfalto; sendo esse comportamento explicado pela posição do sol (nascente e poente). No entanto seu crescimento anual se dá em 
Rev. Elet. em Gestão, Educação e Tecnologia Ambiental (e-ISSN: 2236-1170)

todas as direções. No seu crescimento os galhos são atraídos ao solo e ao tocá-lo se dá o enraizamento, possibilitando a formação de uma planta conjugada à planta mãe, favorecendo a novos pontos absorção de nutrientes.

Ações isoladas do Ministério Público, órgãos ambientais e prefeitura local já desenvolveram projetos para transformar a área onde está assentado o Cajueiro, com mais de uma centena de anos de existência, numa Unidade de Conservação municipal, denominada Monumento Natural Cajueiro de Pirangi, no entanto o município de Parnamirim-RN não desencadeou ações para a efetiva gestão da referida unidade decidindo, assim, desafetar a mesma por meio da Lei Complementar no. 049 de 06 de junho de 2011.

Sendo assim, em virtude dos conflitos existentes na área em discussão e enquanto não se define o modelo gestão da área do Cajueiro de Pirangi, existem ações em andamento para criação de uma Comissão Técnica Provisória Multidisciplinar e Interinstitucional com objetivo de elaborar um Plano de Ações Emergenciais para o Cajueiro de Pirangi. Essa comissão é composta de representantes do Instituto de Desenvolvimento Sustentável e Meio Ambiente do Rio Grande do Norte (IDEMA), Instituto Brasileiro de Assistência Técnica e Extensão Rural do Rio Grande Norte (EMATER), Secretaria de Turismo do Rio Grande do Norte (SETUR), Departamento de Estradas de Rodagem do Rio Grande do Norte (DER), Universidade Federal do Rio Grande do Norte (UFRN) e Empresa de Pesquisa Agropecuária do Rio Grande do Norte (EMPARN).

Como forma de subsidiar elementos para a discussão técnica e aspectos da preservação do cajueiro de Pirangi-RN, este trabalho desenvolveu o levantamento das principais alternativas técnicas para sanear os impactos do crescimento desordenado desse forte elemento turístico da região, buscando manter a atividade na região. Bem como, foram avaliadas as principais rotas de preservação do Cajueiro, mostrando os aspectos relativos a poda como um dos pontos fundamentais de como se portar com o crescimento do mesmo, sem agredir ao Meio Ambiente.

\section{METODOLOGIA}

O método utilizado para pesquisa e coleta de dados pode ser dividido em: pesquisa exploratória qualitativa, através do levantamento de informações sobre a prática adotada na área do cajueiro de Pirangi/RN, com apoio da equipe técnica de suporte do local. Ainda nesta fase executou-se uma pesquisa em livros, teses e leis na busca do embasamento teórico e também um maior conhecimento sobre o tema tratado.

Na segunda etapa foi realizada a pesquisa descritiva quantitativa, obtendo-se a opinião dos usuários, técnicos, guias turísticos e moradores da região acerca das principais medidas adotadas, o questionário aplicado é apresentado na Tabela 1. 
Rev. Elet. em Gestão, Educação e Tecnologia Ambiental (e-ISSN: 2236-1170)

Tabela 1. Questionário aplicado para realização da pesquisa.

\begin{tabular}{|c|c|c|}
\hline Número & Pergunta & Padrão de Resposta \\
\hline 1 & $\begin{array}{c}\text { Você julga o cajueiro um elemento importante } \\
\text { para a atividade turística de Pirangi/RN? }\end{array}$ & Sim ou Não \\
\hline 2 & $\begin{array}{c}\text { Você julga que o conforto da população deveria } \\
\text { ser considerado em primeiro lugar, e que a } \\
\text { contenção do crescimento do cajueiro deveria } \\
\text { ser realizada com podas? }\end{array}$ & Sim ou Não \\
\hline 3 & $\begin{array}{r}\text { Você considera que a melhor alternativa é } \\
\text { redirecionar a área de crescimento do cajueiro? }\end{array}$ \\
\hline
\end{tabular}

Na Figura 1 é apresentada uma imagem do local estudado. Bem como, na Figura 2 uma vista área da referida área e sua influência.

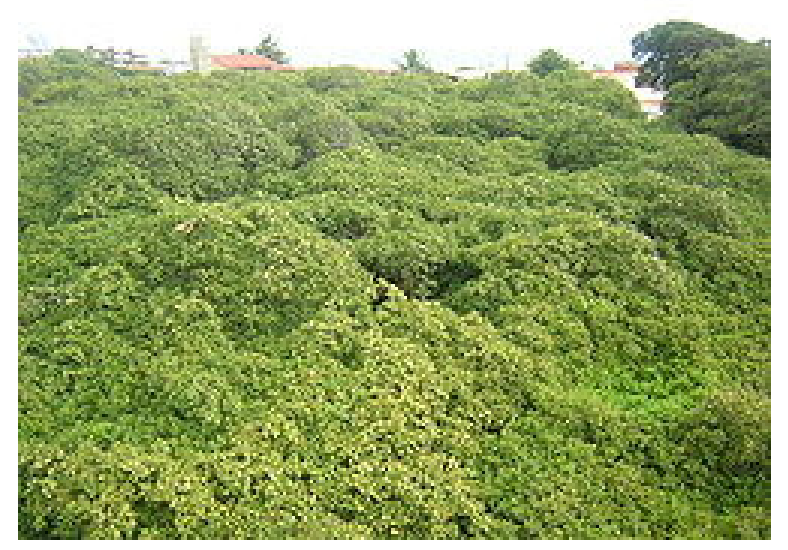

Figura 1. Cajueiro de Pirangi. Fonte: Lima, 1998.

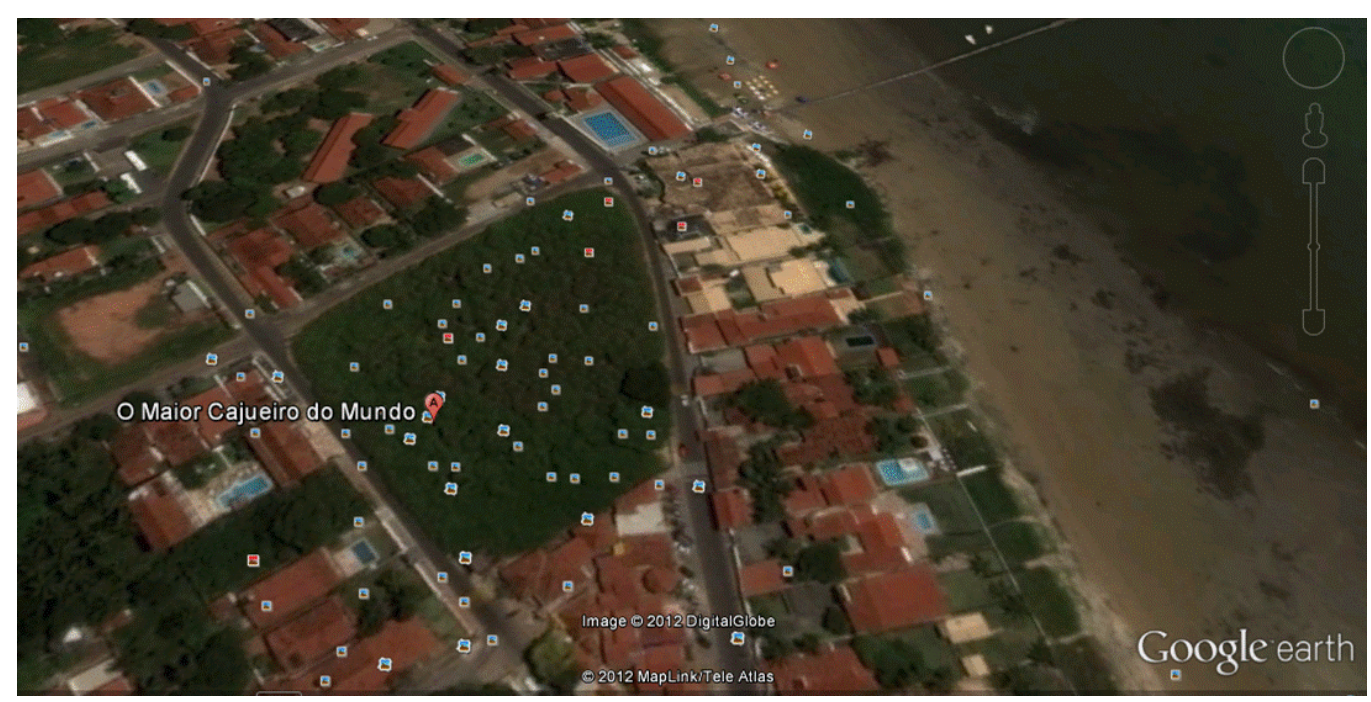

Figura 2. Cajueiro de Pirangi: vista aérea. FONTE: Google, 2012. 
Rev. Elet. em Gestão, Educação e Tecnologia Ambiental (e-ISSN: 2236-1170)

Para definição da matriz de impactos as atividades turísticas foi adotada metodologia adaptada de Tomazonni et al (2008), tendo-se os níveis de impactos padronizados como sendo de alto, médio e baixo risco. A avaliação do risco foi medida pelo binômio severidade e probabilidade.

\section{RESULTADOS E DISCUSSÕES}

Como principal alternativa para contenção do crescimento desordenado da espécie, surge a poda como principal alternativa. Entretanto, alguns riscos inerentes a tal procedimento devem ser considerados para equilibrar tal contexto. Sendo assim, foram analisadas tecnicamente as principais vantagens e desvantagens dessa intervenção.

A poda, conforme descreve SÃO PAULO (2012), em árvores deve ser praticada em função do espalhamento da planta, ou seja, no seu crescimento desordenado devido seu porte e hábito. No caso do cajueiro gigante, para impedir que haja o toque fortemente ao solo, prejudicando a brotação tenra que surge na haste até a uma altura aproximadamente de 1 (um) metro. Além disso, tal procedimento deve melhorar a ventilação, para um melhor arejamento dificulta o desenvolvimento de pragas e doenças, sem comprometer a produção e seus hábitos de frutificação.

A importância de se fazer uma poda, varia de espécie para espécie, assim poderá ser decisiva para uma, enquanto que para outra, ela é praticamente dispensável. Com relação à importância, as espécies podem ser agrupadas à condição da planta, quando são utilizadas prática da poda, respeitando para isso, a época do manejo das plantas adultas, uma vez que, está relacionada ao comportamento fenológico do Cajueiro. Recomenda-se sua realização após a colheita e antes do início do fluxo foliar, momento em que as plantas encontram-se, aparentemente, em repouso vegetativo.

Um contraponto surge, quando questionamentos acerca desse contexto são inseridos nessa discussão, a saber: Por que é necessário o recurso da poda? No seu estado selvagem, as plantas não são podadas e, apesar disso, elas se desenvolvem em perfeitas condições? Porém, para atenuar tais questionamentos é notório que a natureza tem o seu próprio método de poda, onde os ramos pequenos desprendem-se naturalmente e os galhos finos, as folhas e as flores morrem e caem. Vagarosa, mas continuarmente, todas as plantas sofrem um processo de renovação natural. Pela poda não fazemos mais do que acelerar, embora parcialmente esse processo seja normal conforme descreve Luna (1999).

Sendo assim, conforme IDEMA (2009), como uma das principais medidas para conter o avanço do Cajueiro de Pirangi é sugerida a poda de condução (ou formação) e a de limpeza. A poda deve ser processada durante a estação seca, logo após a colheita e antes do início do fluxo foliar, quando as plantas se encontram, aparentemente em repouso vegetativo. A prática da poda, quando utilizada dentro dos padrões técnicos, favorece o aumento da produção e seu desenvolvimento vegetativo. Caso contrário, podem afetar e comprometer a planta.

Existem diversos conceitos para o termo poda, Leite et al (2010) descrevem tais conceitos, dentre os quais esse se destaca pela especificidade na cultura do Cajueiro de Pirangi, como sendo 
Rev. Elet. em Gestão, Educação e Tecnologia Ambiental (e-ISSN: 2236-1170)

a arte e a técnica de orientar e educar a planta, de modo compatível com o fim que se tem em vista, sem nenhum prejuízo para a Fruteira.

A poda de formação ou condução, segundo Rocha et al (2004), é aplicada para direcionar o desenvolvimento da copa contra a tendência natural do modelo arquitetônico da espécie, compatibilizando assim, a formar a estrutura da árvore, assegurando-lhe um aspecto conveniente, dando posição, comprimento e direção ao tronco e aos ramos mestres, nos espaços e estruturas urbanas disponíveis. A esse tipo de poda poderá, também, ser manejada quando apenas, a planta apresentar uma conformação muito irregular ou no caso do Cajueiro de Pirangi, a falta de espaço urbano para se desenvolver.

É uma poda leve, que se orienta no intervalo entre a frutificação e a emissão de rebentos novos, fase que antecede a floração seguinte, conforme valida Mllano; Dalcin (2000), ou seja, no período de repouso vegetativo, anualmente se procede nos pomares, com tesoura, serrote, ou facão bem afiado de poda em punho, consistindo na retirada de um eventual ramo doente, quebrado, seco, praguejado, mal localizado ou inconveniente. É poda sumária, aplicada às plantas adultas daquelas frutíferas que requerem pouca poda, no caso o cajueiro e outras tropicais. Geralmente, todas as fruteiras necessitam deste tipo de poda. É um tipo de poda executada normalmente em períodos de baixa atividade fisiológica da planta, ou seja, logo após sua colheita.

Após a poda de limpeza, deve-se se fazer um tratamento químico (normalmente a base de oxicloreto de cobre), das partes cortadas para reduzir aparecimento de doenças. Basicamente, a poda pode ser executada em duas épocas: no inverno ou no verão, mas é orientada como medida profilática, durante o período seco e antes da florada.

\subsection{Propostas de Intervenções}

Diante o exposto, vimos o tráfego de veículos que circulam nas vias em torno do Cajueiro, como também turistas que passeiam dentro do Cajueiro, para ver de perto a beleza e grandiosidade que é. Hoje, o Cajueiro ocupa uma área de $8.524,31 \mathrm{~m}^{2}$, futuramente estima-se uma área de 10.870,84 $\mathrm{m}^{2}$. Segundo a SETUR-RN (2012) circulam na região cerca de 30 mil turistas na região, em periodos de alta estação; conforme ilustra a Figura 3.

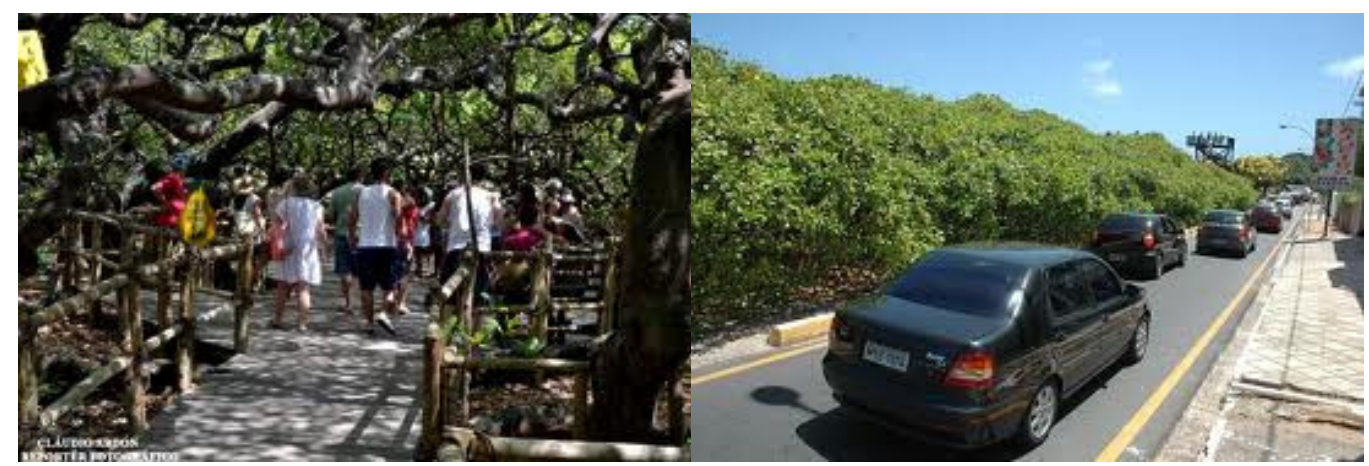

Figura 3. Fluxo de visitação do Cajueiro de Pirangi.

Logo, os objetivos da Poda, unificando conceitos descritos por Souza (1986); MIlano; Dalcin 
Rev. Elet. em Gestão, Educação e Tecnologia Ambiental (e-ISSN: 2236-1170)

(2000) e Leite et al (2010), devem atender quatro premissas principais para o planejamento dessa intervenção, a saber:

- Manter o cajueiro com um porte conveniente, com a base da copa numa altura de $(0,50$ a 1,0m), para ventilação, ao seu trato e manuseio;

- Conduzir o cajueiro a uma forma desejada no ambiente e espaço disponível;

- Suprimir ramos supérfluos, inconvenientes, praguejados, doentes e mortos;

- Manter o padrão de equilibrio de distribuição das pernadas, dando uma configuração arquitetônica da copa para alterar e distribuir o peso das galhas e produção.

Alternativas que poderiam ser aplicadas seriam o redirecionamento para o crescimento da copa do cajueiro, sobrepondo os telhados das casas circunvizinhas ou mesmo a desapropriação da região de entorno. Porém, tais possibilidades foram descartadas pelo elevado custo e riscos associados aos moradores das áreas afetadas. Sendo assim, não foram consideradas nessa análise.

\subsection{Matriz de impactos as atividades turísticas}

Com base na metodologia de elaboração de matrizes de impactos foram avaliadas as conseqüências as atividades turísticas, oriundas da possível podação e contenção do cajueiro, na Tabela 2 são apresentados os cenários identificados.

Tabela 2. Matriz de Impactos as Atividades Turísticas da Podação do Cajueiro.

\begin{tabular}{|c|c|c|c|}
\hline Impacto & $\begin{array}{l}\text { Conseqüências ao } \\
\text { Turismo }\end{array}$ & $\begin{array}{l}\text { Risco (Severidade } x \\
\text { Probabilidade) }\end{array}$ & Medidas Mitigadoras \\
\hline $\begin{array}{l}\text { Interrupção do acesso ao cajueiro durante } \\
\text { o período de intervenções. }\end{array}$ & $\begin{array}{l}\text { 1. Redução do fluxo } \\
\text { de acesso e perdas } \\
\text { com a } \\
\text { comercialização } \\
\text { associada ao } \\
\text { cajueiro. } \\
\text { 2. Frustração dos } \\
\text { visitantes pelo } \\
\text { bloqueio ao acesso. }\end{array}$ & $\begin{array}{l}\text { 1. Alto } \\
\text { 2. Médio }\end{array}$ & $\begin{array}{l}\text { 1. Criação de área comercial } \\
\text { alternativa. Bem como, } \\
\text { zoneamento do processo de } \\
\text { poda, em etapas. } \\
\text { 2. Campanha educativa para } \\
\text { esclarecimento das medidas } \\
\text { adotadas e seu objetivo. }\end{array}$ \\
\hline $\begin{array}{l}\text { Ocorrência de doenças oriundas do } \\
\text { processo de podação. }\end{array}$ & $\begin{array}{l}\text { 3. Limitação do } \\
\text { acesso ao cajueiro. }\end{array}$ & 3. Médio & $\begin{array}{l}\text { 3. Risco maior durante } \\
\text { épocas de baixa estação. } \\
\text { Desenvolvimento de rotas } \\
\text { alternativas para visitação. }\end{array}$ \\
\hline Risco de morte da espécie. & $\begin{array}{l}\text { 4. Eliminação do } \\
\text { marco turístico da } \\
\text { região. }\end{array}$ & 4. Baixo & $\begin{array}{l}\text { 4. Acompanhamento de } \\
\text { profissionais especializados, } \\
\text { com o monitoramento da } \\
\text { qualidade da espécie e } \\
\text { ocorrência de indícios de } \\
\text { doenças. }\end{array}$ \\
\hline
\end{tabular}


Rev. Elet. em Gestão, Educação e Tecnologia Ambiental (e-ISSN: 2236-1170)

\begin{tabular}{|c|c|c|c|}
\hline $\begin{array}{c}\text { Risco da espécie perder o posto para } \\
\text { outras árvores em processo de } \\
\text { crescimento. }\end{array}$ & $\begin{array}{c}\text { 5. Perda do } \\
\text { referencial que faz } \\
\text { a espécie algo de } \\
\text { interesse a } \\
\text { visitação. }\end{array}$ & $\begin{array}{c}\text { 5. Baixo } \\
\text { recursos naturais da região, } \\
\text { como atrativo combinado. A } \\
\text { saber: passeios em } \\
\text { embarcações, praias, lagoas } \\
\text { etc. }\end{array}$ \\
\hline
\end{tabular}

Diante dos resultados, observa-se que adotadas as medidas preventivas o procedimento de podação pouco deve impactar a espécie e o turismo local. Tais resultados seguem uma linha descrita por Molina (2003) e Molina (2004); que definem o grau de conseqüência das medidas para manutenção dos índices de visitação e qualidade do turismo estabilizado ou em rotas de crescimento.

\section{CONCLUSÃO}

Diante da análise das alternativas técnicas e seus impactos a atividade turística da região onde se encontra o cajueiro de Pirangi, pode-se concluir que:

1. A podação é a técnica mais adequada para conter o crescimento desordenado da espécie e manter ativa esse poderoso elemento turístico da região;

2. As intervenções devem ser bem planejadas, sobretudo, com a escolha de períodos adequados para mitigar efeitos adversos no cajueiro;

3. O principal impacto as atividades turísticas, ou seja, com maior severidade e grau de probabilidade de ocorrência (risco), foi a redução do fluxo de acesso e perdas com a comercialização associada ao cajueiro; dentre as analisadas;

4. São necessárias ações mitigadoras para o gerenciamento das conseqüências de médio impactos mapeadas neste trabalho.

5. A metodologia empregada não considerou as hipóteses de reordenamento da copa do cajueiro ou mecanismos de desapropriação de áreas circunvizinhas.

Uma referência parafraseada de José Simplício de Holanda define a percepção sobre o referido problema: "Deus dotou o homem de inteligência para usufruir da natureza passando a criar animais e a cultivar vegetais para a sua sobrevivência. Afinal de contas o que desejamos? Se for uma sobrevivência pacífica e sustentável É NECESSARIO DOMESTICAR O CAJUEIRO DE PIRANGI."

\section{REFERÊNCIAS BIBLIOGRÁFICAS}

1. BARROS, L. M. Caju. Produção: aspectos técnicos. Brasília: Embrapa Informação Tecnológica, 2002. 148p. 
Rev. Elet. em Gestão, Educação e Tecnologia Ambiental (e-ISSN: 2236-1170)

2. BARROS, L. M.; CRISÓSTOMO, J. R. Melhoramento genético do cajueiro. In: ARAÚJO, J. P. P.; SILVA, V. V. Cajucultura: modernas técnicas de produção. Fortaleza: EMBRAPA-CNPAT, 1995. p.73-96.

3. BIONDI, D. Diagnóstico da arborização de ruas da Cidade de Recife. 1985. 167f. Dissertação (Mestrado em Engenharia Florestal) - Universidade Federal do Paraná, Curitiba, 1985.

4. CEMIG. Manual de arborização. Belo Horizonte: Diretoria de Desenvolvimento do IEF, [1995], 23p.

5. CEMIG. Programa de compatibilização da arborização com a rede de distribuição de energia aérea. Belo Horizonte: Superintendência de Coordenação de Ações e Estudos sobre Meio Ambiente, 1994. 30 p.

6. CHIA, Robert. A 'rhizomic' model of organizational change and transformation: perspective from a metaphysics of change. British Academy of Management, v.10, 1999.

7. FERREIRA, F. A. Patologia Florestal: principais doenças florestais no Brasil. Sociedade de Investigações Florestais: Viçosa-MG. 570p., 1989.

8. IDEMA. Plano de ações emergencias da unidade de conservação integral "monumento natural cajueiro de pirangi". Relatorio Técnico. 2009.

9. LEITE, V. D. et al. Gestão de serviços de limpeza urbana em cidades de médio porte. RGSA. v.4, n. 3, 2010.

10. LIMA, V. P. M. S. A cultura do Cajueiro no Nordeste do Brasil. 2. ed. Fortaleza: BNB-ETENE, 1998. n.3. 458p.

11. LUNA, J. V. U. Manual de fruticultura tropical. Circular técnica n.4. EBDA, Salvador, 1997. 91p.

12. MEDEIROS NETO, S. O. Relatório técnico de visita ao maior cajueiro do mundo. Natal, 2008. 18p.

13. MEDEIROS NETO, SOUZA. Olavo de, Vaudi Araujo de, Relatório técnico de visita ao maior cajueiro do mundo. Natal, 2008. 18p.

14. MILANO, M.; DALCIN, E. Arborização de vias públicas. Rio de Janeiro: LIGHT, 2000. 226 p.

15. MOLINA, S. O pós- turismo. São Paulo: Aleph, 2003.

16. MOLINA, S. Pós-turismo: novas tecnologias e novos comportamentos sociais. In: MOESCH, Marutschka M e GASTAL, Susana (orgs.). Um outro turismo é possível. São Paulo: Contexto, 2004. pp. 25 - 31.

17. OLIVEIRA, V. H. C. Manual de Produção Integrada de caju. Fortaleza: Embrapa Agroindústria Tropical, 2005.

18. ROCHA, Rodrigo Tavares da; LELES, Paulo Sérgio dos Santos; OLIVEIRA NETO, Sílvio Nolasco de. Arborização de vias púbicas em Nova Iguaçu, RJ: o caso dos bairros Rancho Novo e Centro. Rev. Árvore, Viçosa, v. 28, $\quad$ n. 4, ago. 2004 . $\quad$ Disponível em <http://www.scielo.br/scielo.php?script=sci_arttext\&pid=S010067622004000400014\&lng=pt\&nrm=iso>. acessos em 01 jul. 2012.

19. SÃO PAULO. PREFEITURA DO MUNICíPIO DE SÃO PAULO \Manual Técnico de Arborização Urbana. Secretaria Municipal do Verde e do Meio Ambiente. 2012.

20. SEMARH. SECRETARIA DE ESTADO DO MEIO AMBIENTE E DOS RECURSOS HIDRICOS, SEMARH. Bacias hidrográficas do Estado do Rio Grande do Norte. Acessivel em: http://www.semarh.rn.gov.br. Acesso em: $30 / 06 / 2012$.

21. SETUR. Dados turísticos do Rio Grande do Norte. 2011. Disponível em: http://www.rn.gov.br/. Acesso em 20/06/2012.

22. TOMAZZONI, E. L. et al. Turísticos com base nos conceitos de mudança, de incerteza e na teoria do caos: estudo dos exemplos de gramado e canela, na serra gaúcha. O\&S - v.15 - n.47 - Outubro/Dezembro - 2008. 